\title{
A REVISÃO DOS ARGUMENTOS NA POLITEĹA V: VLASTOS E O FEMINISMO EM PLATÃO
}

\author{
Magda Guadalupe dos Santos* * PUCMinas.
}

\begin{abstract}
RESUMO: As análises de Gregory Vlastos sobre os textos dos Antigos são aqui trazidas ao primeiro plano em moldes de analogia. Seus estudos sobre Platão nos propiciam uma abertura dialógica inclusive às considerações e estudos feministas surgidos nas últimas décadas. Este trabalho propõe refletir acerca da passagem $456 \mathrm{~b}$ que versa sobre a mulher filósofa ou inimiga da filosofia (philósophós te kaì misósophos) e que bem realça o campo normativo desenvolvido por Platão em Politeía V. $\mathrm{Na}$ preocupação pela cidade justa, explorando os efeitos de uma paridade de funções entre os gêneros, Platão nos incita a investigar o teor de seriedade da questão, considerando a própria Politeía e sua recepção na análise contemporânea. Tomam-se as análises de Vlastos como suporte interpretativo de tais questões.
\end{abstract}

PALAVRAS-CHAVE: analogia; mulher filósofa; gênero; paridade.

\section{THE REVISION OF ARGUMENTS IN POLITEIA $V$ :$$
\text { VLASTOS AND FEMINISM IN PLATO }
$$

\begin{abstract}
We analyze the work of Gregory Vlastos about ancient texts. His studies about Plato offer us a dialogical opening, which in particular can be considered from the viewpoint of feminism studies from the last decades. This work is focused on the reflection of the passage $456 \mathrm{~b}$, which writes about a philosopher woman or enemy of the philosophy (philósophós te kai misósophos) and that highlights the normative field established by Plato in Politeia $V$. With the objective of a fair city and exploring the effects of parity of functions and genders, Plato incites us to explore the seriousness of these questions, considering Politeia itself and its reception in the contemporary analysis. The interpretations of Vlastos are taken as an interpretative support to those questions.
\end{abstract}

KEYWORDS: analogy; philosopher woman; gender; parity. 
Among all of Plato's writings and among all the writings which have survived from the classical age of Greece, that work alone projects a vision of society in whose dominant segment the equal rights of human beings are not denied or abridged on account of sex. (VLASTOS, 1994, p. 22).

Dentre todos os escritos de Platão e entre todos os escritos que sobreviveram desde a época clássica da Grécia, apenas este trabalho projeta uma visão da sociedade em que, considerando-se seus segmentos dominantes, direitos iguais dos seres humanos não são negados ou restringidos por causa do sexo. (VLASTOS, 1994, p.22).

homenagem a um filósofo, a um professor de filosofia, é sempre façanha curiosa
de distintas maneiras. De certo modo, há o relevo a ser conferido e evidenciado ao
conjunto dos trabalhos de Gregory Vlastos, divulgados pelo mundo. De outro, há o sentido a ser perquirido, de se propor homenagear um filósofo no século XXI, época das evidências tecnocráticas e da arrogância do poder econômico.

No que se refere a algumas obras de Vlastos, proponho aqui discutir alguns de seus aspectos. Acerca do sentido de se homenagear um filósofo do nosso tempo e, principalmente, um filósofo que sempre se envolveu com o pensamento dos Antigos, temos a possibilidade de aguçar em nós o que nos chama a atenção na filosofia - algo concernente à exigência de discernimento de um êthos que se queira manter ou reconstruir, com reverência às provocações de uma razão demonstrativa historicamente delineada e que deve ser validada a cada dia pela reflexividade de nossas contínuas indagações; e quando escrevo reflexividade, entendo mesmo algo como uma "propriedade da relação de equivalência" entre modos de ser e de valorar o mundo.

Diante da obra de Vlastos, contudo, há também que se reconhecer uma radicalidade da intenção filosófica projetando-se na construção interpretativa do pensamento clássico e da transmissão de formas de se ler o mundo temporalizado por meio de determinados focos exegéticos. Cria-se no contraste das especificidades de seus textos, face à intenção de ser filósofo num mundo tão distinto daquele dos Antigos gregos, um patamar de reproduções mentais que nos levam a buscar alguns pontos de relevo para o desenvolvimento temático. Mas, sobretudo, merece ser mencionado, a homenagem se dá pelo fato de, como bem pontua

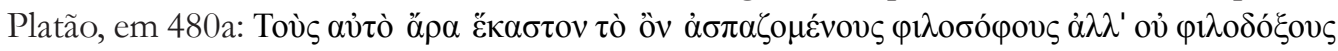

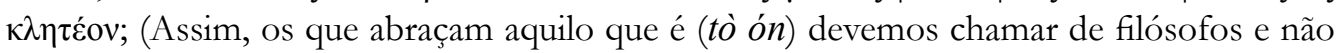
de amigos da opinião?).

Ora bem, no que concerne ao veio filosófico-interpretativo de Vlastos, vale indagar, inicialmente, se estaríamos diante de um filósofo com estilo capaz de ousar "escavar, destruir, romper e buscar, para além do texto, um subtexto que resulte verdadeiro"? No propósito validado, mas, sobretudo criticado por Wolgang Iser, ${ }^{1}$ a interpretação equivale a "restaurar o fenômeno com intenção de encontrar seu equivalente" e, no processo de compreensão, afirma por sua vez Susan Sontag encontrar-se-iam as bases interpretativas, já que "compreender é interpretar". ${ }^{2}$ Tanto Sontag, quanto Iser recusam a concepção de

\footnotetext{
${ }^{1}$ ISER, 1984, p.23.

${ }^{2}$ SONTAG, 1966, p.6.
} 
bases interpretativas como órganon de decifração da verdade, a qual estaria pretensamente se manifestando no texto. Restariam, pois, as interrogações acerca do método do intérprete ao interrogar-se sobre suas causas determinantes. Nesse sentido, é interessante investigar se as bases interpretativas do pensamento de Vlastos estariam, assim, nos propondo questões acerca de suas próprias possibilidades interpretativas. E se seriam essas as bases para se compreender a complexidade do texto platônico.

Esse intento vincula-se a um outro, o saber se e como pelo pensamento de Vlastos podem ser revistos, no sentido de apreciados, alguns dos argumentos da Politeía V acerca das discussões feministas, as quais se supõem são apresentadas no texto platônico. Leva-se em consideração o embate filosófico travado entre concepções interpretativas distintas e, em especial, aquela estabelecida entre o pensamento de Gregory Vlastos e o de Sarah Pomeroy. $\mathrm{Na}$ verdade, é da relação dialógica entre os dois filósofos - Vlastos e Pomeroy - que a homenagem aos propósitos da hermenêutica contemporânea poderia, aqui, se configurar, mas firmando suas bases na interpretação do exercício pleno do bios politikós enquanto atividade por excelência da tradição grega. Serão, sobretudo, como leitores da filosofia platônica que tanto Vlastos como Pomeroy encontrarão possibilidade e mesmo necessidade de um longo e recíproco enfrentamento tético ou antitético - e penso aqui num sentido Fichteano, encontrado em $W$ issenschaftslehre, ${ }^{3}$ ao se referir ao juízo no qual alguma coisa não é posta como igual ou contrária a outra, mas somente como igual a si mesma. Assim, o que se tenciona investigar é o modo como as duas posições interpretativas realçam o intuito de revitalizar o encontro da filosofia com a história, da filosofia com os vários tempos do entendimento humano e, pois, da filosofia com o dia-légein, na relação paradoxal entre dicotomias interpretativas e interações textuais, tendo cada uma de tais posições certeza e convicção de sua determinação, de sua suposta certeza tética do eu reflexivo e intérprete do mundo antigo. Não me parece aqui descontextualizada a afirmação platônica também do livro

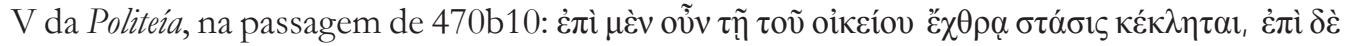

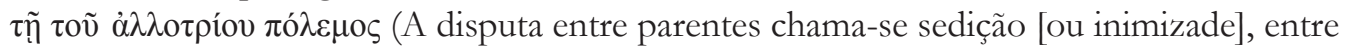
estranhos, guerra). Resta saber quem assumiria aqui a feição helena ou a feição bárbara. $\mathrm{E}$ claro, o que a passagem 470c nos traz é mesmo a indicação de que o termo bárbaros possa significar tanto não-grego, quanto, por derivação dessa primeira acepção, também bruto, rude.

Não sei bem se poderíamos ressignificar as interpretações tanto de um, quanto de outro, em especial as de Pomeroy, como de brutas, rudes, bárbaras! (se bem que para mim elas são mesmo... bárbaras!). As bases interpretativas entre o filósofo e sua adversária feminista ressoam distintas e antagônicas, mas parecem necessárias uma à outra para que um texto em movimento, expressivo da complexidade argumentativa e temporalizada, possa se sobressair. Eu não poderia esconder, e jamais seria essa a minha intenção, que minha leitura de Gregory Vlastos, desde o primeiro momento, se deu em função desse confronto com os textos de Sara Pomeroy e das variações interpretativas que feministas helenistas criaram, em tempos

\footnotetext{
${ }^{3}$ FICHTE,1997. Em Wissenschaftslehre, 1794, I, S 3, D7, Fichte entende que o supremo juízo tético seria equivalente a "eu sou", no qual nada se afirma do eu, mas se deixa vazio o lugar do predicado para a possível determinação do eu ao infinito. Ou seja, este juízo seria a "absoluta posição do eu".
} 
distintos, em torno dessa interlocução. Certa dualidade de expressão em busca de uma dicção de gênero me parece aqui sedutora, mas não poderia também deixar de reconhecer a maestria interpretativa do filósofo em função do texto platônico.

Assim, é nesse confronto de idéias que se evidencia o pensamento de Platão como meio dialógico no mundo letrado, ao redor do qual o embate do pensamento do filósofointérprete e das comentadoras feministas torna-se palco de considerações. Com suas certezas mais profundas, elevando-as a um patamar de criticidade nas formas de tratamento interpretativo, tais filósofos ressaltam a complexidade da leitura dos textos dos Antigos.

Justamente no embate dialógico dos textos, evidenciam-se os contornos da Pbilosophía como crítica e herdeira dos horizontes nomotéticos da Antiguidade. Assim, como menciona Vaz, os laços de reflexão, que surgem no texto platônico em torno da figura do justo e do bem, voltam-se também para as relações entre o mundo em que vivemos, a cidade em que habitamos e o indivíduo que cada um é. Tais relações constroem-se de modo tal que, assegurando-se ao primeiro a sua "ordem (táxis, tal como no Górgias 507 e6-508a8), à cidade a boa constituição (politeía) e ao indivíduo a virtude (aretée)", ${ }^{4}$ tem-se por ativo verdadeiro projeto de hermenêutica filosófica do êthos da cultura.

Esta análise divide-se, assim, em dois níveis de leitura. No primeiro, de bases conceituais, pondera-se acerca da revisão interpretativa dos argumentos na Politeia V. No segundo, de feições hermenêuticas, intenta-se uma breve análise acerca da axiologia que se evidencia nos textos de Vlastos sobre o feminismo em Platão.

\section{A revisão dos argumentos da Politeía V}

No texto intitulado The Argument in the Republic that "justice pays", ${ }_{5}^{5}$ Vlastos entende que o lema platônico que sustenta a cidade ideal, concernente à questão de se dever "ter justiça na alma" ("having justice in the soul"), é o que dá garantias para se sustentar que a "justiça compensa" ("justice pays"). Para ele, levando-se em consideração as correlações que o livro IV da Politeía dispõe, o senso de justiça aí inscrito não equivale a um bem evidenciado em ações, mas em agentes, e isso representa a disposição ativa para se "comportar com justiça face a companheiros". ${ }^{6}$ Segundo Vlastos, psicologia e dimensão social se integram na complexidade conceitual do justo e, ao se referir a seus diferentes aspectos (ou seja, aos aspectos do justo), Platão estaria indicando como se pode ser justo em face de um outro e também face às disposições da alma em si mesma e em processo de interação. Enquanto uma incansável tarefa filosófica, as indagações passam então a surgir a partir das assertivas de Vlastos. Pode-se com elas e por meio delas indagar:

\footnotetext{
${ }^{4}$ VAZ, 2011, p.159

${ }^{5}$ VLASTOS, 1968, p. 665, v.65, n.21.

${ }^{6}$ VLASTOS, 1968, p. 665, v.65, n.21. Justice is a property not of actions as such, but of agents; it stands for the active disposition to behave justly toward one's fellows.
} 
a) qual seria o nível de possibilidade a ser alcançado frente a tamanha complexidade de justiça?

b) no livro $V$, na relação paritária entre mulheres e homens da classe dos guardiões, seria tal exigência de justiça validada enquanto uma harmonia política e psicológica construída em si mesma e em relação aos outros?

c) se a justiça, como um bem em si e não apenas por suas consequências, constitui-se como uma polêmica relacional, como regulamentar, nas formas paritárias de exercício de funções de mulheres e homens guardiões da cidade justa, tamanha complexidade metafísico-política?

Acredito que as questões delineadas e discutidas nesse texto, publicado em 1968, encontram repercussão em outro texto, Was Plato a feminist? em que discute a interpretação de Pomeroy acerca das mulheres guardiãs. Este texto é retomado em vários momentos e em diversas compilações, seja na coletânea de Nancy Tuana, Feminist interpretations of Plato, publicada em 1994, seja na coletânea de Richard Kraut, Plato's Republic: Critical Essays, publicada em 1997. Na primeira compilação, Vlastos polemiza com as visões das helenistas feministas, em especial aquelas das universidades norte-americanas, como Arlene Saxonhouse, Janet Farrell Smith e Nathalie Harris Buestone e outras, penso que, justamente por isso, este se tornou um texto instigante para análises contemporâneas acerca das possibilidades interpretativas das obras de Platão.

O método utilizado por Vlastos é o que se destaca no processo de compreensão de suas bases e possibilidades interpretativas. É justamente pelo enfoque metodológico que penso ser possível relacionar os dois textos citados entre si, bem como aos das feministas helenistas, tomando, contudo, a questão da interlocução e do diálogo como ponto de relevo.

\subsection{Primeira perspectiva de leitura: plano conceitual}

$\mathrm{Na}$ leitura de bases conceituais, vale apontar a indicação das bases textuais, tanto em feições conceituais, quanto em feições histórico-culturais, que passam a delimitar as indagações acerca das interpretações dos nossos filósofos. Nesse sentido, cumpre estabelecer um primeiro parâmetro.

No âmbito das correlações já propostas nos livros anteriores, evidencia-se no livro $\mathrm{V}$ o impacto receptivo que visa alcançar a base filosófica do texto platônico, em especial no que concerne à primeira e segunda ondas, que correspondem à educação igualitária na classe dos guardiões e à comunidade das mulheres guardiãs. Há de se considerar que, quanto mais se lê a República, mais se pode reconhecer que o papel das mulheres, como proposto por Platão, não se assenta em uma configuração simples de ser apreendida e assimilada em seu espectro de significados. De fato, alguns passos mereceriam ser lidos de uma perspectiva crítica - que ensejaria um discernimento ou uma apreciação de seu assentamento tópico na estrutura da obra, a qual se pode moldar em modelos epistemológicos distintos. 
Mas é da perspectiva dialógica entre perspectivas diferenciadas que aqui se estabelece o fio condutor da análise. Tomo então um excerto do texto platônico, por ser específica, do corpus filosófico, a leitura do texto em sua materialidade. Leva-se em consideração a questão da autenticidade como um dado essencial nos fundamentos que sustentam o pensamento filosófico como esse saber rigoroso e em vias de recepção histórica.

Tem-se, no livro V, o passo 456a5, apresentado como verdadeira aporia: Tí dé;

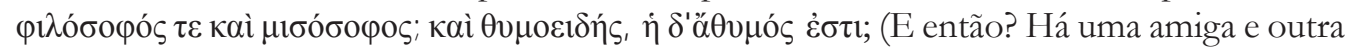
inimiga da sabedoria? E irascível ou pusilânime?). Confronta-se aqui uma aporia porque o passo se apresenta com uma expressiva dificuldade teórica, qual seja, formula-se uma indagação, precedida, contudo, por uma afirmação que a contradiz e sucedida por outra equivalente afirmação também de teor antinômico. Com efeito, na passagem imediatamente anterior, em Politeía, 455e, afirmara-se que

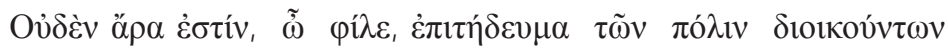

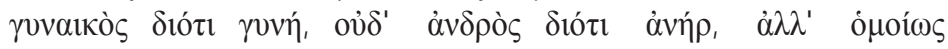

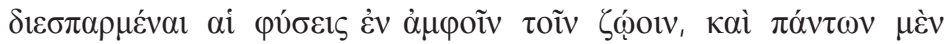

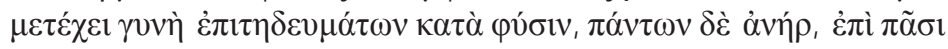

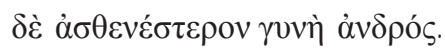

Não há mesmo, meu amigo, nenhuma ocupação dos que administram a cidade que seja da mulher porque mulher, nem do homem porque homem, mas por igual as naturezas (bai phýseis) estão disseminadas em ambos os viventes, e a mulher participa de todas as ocupações conforme a natureza (katàphýsin), e participa de todas o homem, mas em todas a mulher é algo mais débil (asthenésteron) do que o homem.

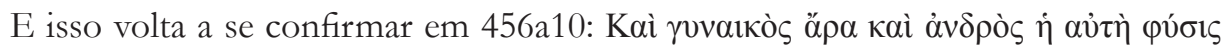

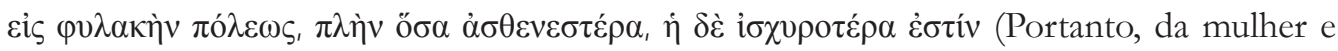
do homem a natureza voltada para a guarda da cidade é a mesma, exceto em quanto uma é mais débil e a outra mais forte).

Ora, o que se encontra entre essas duas declarações são perguntas que, uma vez que recebam o assentimento do interlocutor, estabelecem as bases para que se demonstre que não é impossível (adýnata) que as mulheres dos guardiões (tôn phylákon gynaîkes) tenham a mesma educação que eles. Assim, na sequência: a) afirma-se: "mas julgo pois que há, como diremos, tanto uma mulher dotada para a medicina (gynè iatrikế), e outra não, quanto dotada para a música (mousikề), e outra não-dotada (ámousos) por natureza (phýset); b) em seguida, perguntase: "e não há então uma dotada para a ginástica (gymnastikế) e para a guerra (polemikề), e outra não-dotada para a guerra (apólemos) nem amiga da ginástica (ou philogymnastikêe?; c) continuase com outra pergunta: "e então? tanto amiga da sabedoria (philósophos) quanto inimiga da sabedoria (misósophos)? e uma é irascível (thymoeidés) e a outra sem ânimo (áthymos)?; d) assim se chega à conclusão de que é possível haver a "mulher guardiã" (phylakikè gynê), pois há as que apresentam a natureza tal qual se escolheu para os homens (toiáuten phýsin), "exceto em quanto uma é mais débil e a outra mais forte (plén hósa asthenestéra, he dé iskburotéra 
estin)". Essa debilidade, já que própria da natureza (phýsis) da mulher, em comparação com a do homem, estende-se a todas as possibilidades apontadas, a saber, o fato de ela ser dotada para a medicina e a música, para a ginástica, para a guerra e a filosofia, bem como no que se refere à irascibilidade que se exige do guardião. Portanto, a questão de ser ou não possível que haja uma mulher filósofa tem uma resposta positiva, mas sempre com a restrição que de acordo com a sua natureza mais débil (asthenés significando sem força, tanto no sentido corporal, ou seja, um corpo fraco, doentio, quando intelectual, alguém fraco de espírito, e social, sem poder, sem crédito, sem fortuna, sem valor).

A partir desse excerto, as interpretações merecem ser chamadas e a dimensão imagética do texto se configura. Depara-se com uma polifonia de consciências que demonstra a complexidade textual. No processo das relações dialógicas, merecem ser trazidos os comentários de Arlene Saxonhouse ${ }^{7}$, ao enfatizar que no texto da Politeía "fraqueza e debilidade femininas são, ao logo do texto, continuamente afirmadas por Sócrates", como em 455e, 456a, 457a e 469d. Entretanto, simultaneamente, Sócrates argumenta não haver, pela natureza, necessariamente diferenças entre os gêneros!

Para a comentadora, em 388a e 605e as mulheres são mostradas como aquelas que "facilmente sucumbem à dor, enquanto os homens permanecem fortes!"' São elas também, e principalmente, destituídas de desejo. Sua indagação indo mais longe, explicita-se, em seu entendimento, que a tentativa platônica é de simples assimilação das qualidades masculinas pelas mulheres, o que lhe permite inferir como o filósofo (Sócrates) tenta fazer "as mulheres se tornarem homens", fazendo delas "participantes igualitárias na comunidade política".

\subsection{Segundo plano de leitura: hermenêutico}

$\mathrm{Na}$ segunda perspectiva, a de leitura hermenêutica propriamente dita, assegurada logicamente sobre o fundamento da leitura das significações textuais e conceituais, merecem ser buscadas razões que elucidem, para nós, a dinâmica e mesmo a atualidade do texto platônico, que Vlastos visa a evidenciar.

Se pudermos considerar que o propósito platônico é o de construção de um tenso diálogo, tem-se aí uma primeira possibilidade de reconhecimento da recepção de algumas vozes. No confronto com o pensamento de Vlastos, em especial em seu Was Plato a feminist?, recepcionam-se outras tantas vozes em um modelo de paideía, analogicamente formado, referendado no êthos da cultura grega. Dali, Vlastos tenta extrair certa intenção platônica de oferecer uma dimensão de justiça que possa valer à pena. Suas referências são bem específicas. Em relação a guardiões e guardiãs, que se inserem nas duas primeiras ondas do livro V, o Platão de Vlastos conta com paradigmas de inteligência e caráter, desde que a espetacular

\footnotetext{
${ }^{7}$ SAXONHOUSE, 1994. p.67.

${ }^{8}$ SAXONHOUSE, 1994, p.68.

${ }^{9}$ SAXONHOUSE, 1994, p.68.
} 
paideia lhes possa ser garantida na cidade ideal, sempre visando a melhoria do caráter moral de cada um deles.

Nessa interpretação, leva-se em consideração estar Platão dando às mulheres uma oportunidade para demonstrarem suas virtudes morais, ou ainda, a possibilidade da existência nelas de tais virtudes, embora sejam elas mulheres. Suas indagações não deixam de ser curiosas. Entre outras, ele questiona: "Porque Platão teria assumido que ser do sexo feminino diminuiria as chances de alguém transformar-se em uma pessoa especial, em vez de numa pessoa comum?"10

Poderíamos completar essa indagação e insistir se, nessa condição de pessoa especial, a que ele se refere, poderia a mulher realmente almejar ser filósofa, nos termos do passo 456a? E se haveria em tal possibilidade ou impossibilidade uma dimensão de ou uma preocupação pela justiça, na qual se insere a tônica de tais indagações?

Por seu método analógico, Vlastos estabelece uma lista de direitos negados à mulher ateniense, enaltecendo, contudo, com certas inferências, a proposta platônica de garantir os mesmos direitos para as guardiãs. Direitos como o de educação, enquanto monopólio masculino, encontrariam seu ponto de partida na paideía platônica. Direitos à oportunidade vocacional, à capacidade legal, à escolha sexual, seriam também, na Politeía, contemplados como possibilidade paritária para ambos os gêneros, não precisando ficar as mulheres sob o cuidado de um kýrios que suprisse as deficiências de sua menoridade política.

Nesse ponto, as questões de Sarah Pomeroy parecem-lhe despropositadas. No entendimento de Vlastos, Pomeroy se refere às mulheres e filhos como se pertencessem em comum ao homem, sem jamais aludir, em contrapartida, ao fato de que os homens e também as crianças, pertenceriam em comum às mulheres. Pomeroy estaria suspeitando de termos como koinonía (comunidade) de crianças e mulheres dos guardiões (450c); ktésis (posse) e khréia (uso) de crianças e de mulheres (451c.).

Para Vlastos, frente a esta assimetria de referências de "quem pertence a quem", 11 Pomeroy entende que as mulheres guardiãs são propriedades dos homens guardiões. Para ele, tal inferência seria injustificável ou mesmo não autorizada, ${ }^{12}$ não havendo, segundo menciona, esse senso de pertencimento na Politeía. ${ }^{13}$

De fato, em texto publicado em 1991, no American Journal of Pbilology, Pomeroy ${ }^{14}$ argumenta que seu trabalho acerca da história das mulheres na Antiguidade (grega e romana) lhe permitiu se deparar com espaços vazios (blank spaces) ou preenchidos indevidamente, sem justificação adequada, por métodos de pesquisas duvidosos. Ademais, a falta de distinção entre estudos sobre mulheres feitos pelos homens, daqueles feitos por mulheres, interfere, a seu sentir, na forma imagética e nas generalizações de suas considerações. Em seu livro

\footnotetext{
${ }^{10}$ VLASTOS, 1994, p. 14.

${ }^{11}$ VLASTOS, 1994, p. 15. "Who-belongs-to-whom”.

${ }^{12}$ VLASTOS, 1994, p. 15. The inference is unwarranted!.

${ }^{13}$ VLASTOS, 1994, p. 15. There is no other relevant sense of "belonging".

${ }^{14}$ POMEROY, 1991, p. 266, v.112, n.2.
} 
Whores, Wives and Slaves: Women in Classical Antiquity, Pomeroy ${ }^{15}$ analisa a condição legal e privada da vida das mulheres em Atenas do período clássico, o tratamento a elas conferido na tragédia, na comédia e nos tratados (treatises) filosóficos. Sem entrar no âmago de suas análises, sua contínua insistência de que o "passado deve ser entendido em seus próprios termos" $" 16$ parece bastante razoável.

Nesse sentido, a tentativa dialógica de Vlastos de enaltecer as propostas platônicas de educação, face à condição da mulher na tradição ateniense, merece, então, ser retomada pelo viés da recepção. Estariam, assim, Vlastos, Pomeroy (e mesmo toda a ala da hermenêutica helenista-feminista que se reúne em torno dela) tomando como seus os mesmos leitores? Não seriam esses possíveis leitores mais do que uma imagem de si mesmos, como um segundo ego? Mas se assim for, não faltaria aqui, no confronto do texto com o seu leitor, um "potencial de efeitos" que, conforme Iser, ${ }^{17}$ gere diferenciações de atitudes historicamente constituídas?

$\mathrm{Na}$ verdade, como forma de trazer alguma pontuação final, penso que o confronto dos textos de Vlastos com os de Platão equivale ao confronto que temos, como leitores de Vlastos, lendo os diálogos platônicos. O que de tudo resulta deveria ser sempre um horizonte aberto a novas possibilidades reflexivas, para que distintos níveis de discussão possam sempre ganhar oposições e críticas nas vias de abordagem textual.

Eis que, desta feita, pode-se bem visualizar um espectro de possibilidades, nas quais novos traços interpretativos, sempre em movimento, dialeticamente dispostos, possam nos ajudar a unir a lógica imanente da Politeía e fazer com que suas significações se submetam ao rigor de um questionamento necessário do valor da justiça, do bem, da identidade na diferença.

Se a justiça realmente compensa, é preciso verificar, assim, que bases conceituais, que nunca permanecem estanques sobre si mesmas, tecem, de certa forma, a trama metodológica dos textos platônicos que provocam em nós leituras temporalizadas como expressão da consciência histórica e contextualizada que temos dos Antigos. Nessa complexa trama também o nosso ethos se constrói como a própria aventura bumana.

\section{REFERÊNCIAS}

CAVARERO, A. Nonostante Platone. Figure femminili nella filosofia Antica. Roma: Ombre Corte, 2009.

FICHTE, J. G. Wissenschaftslehre, 1794, I, §3, D7, Stuttgart: Steiner-Verlag, 1987.

ISER, W. Der Akt des Lesens. Theorie ästhetischer Wirkung. 2.Aufl. München: Fink, 1984.

PLATÃO. A República. Tradução de Maria Helena da Rocha Pereira. 3.ed. Lisboa: Calouste Goubenkian, 1980.

\footnotetext{
${ }^{15}$ POMEROY, 1975.

${ }^{16}$ POMEROY, 1975, p. 92.

${ }^{17}$ ISER, 1984, p. 7.
} 
PLATON. Le République. Texte établi et traduit par Émile Chambry. Paris: Les Belles Lettres, 1933.

POMEROY, S. B. The Study of Women in Antiquity: Past, Present, and Future. The American Journal of Philology, 112, n. 2, p. 263-268, Summer, 1991. Press Stable URL: <http://www. jstor.org/stable/294724>. Accessed: 18 fev. 2011.

POMEROY, S. B. Whores, Wives and Slaves: Women in Classical Antiquity. New York: Schocken, 1975.

SANTA CRUZ, M. I. Feminismo y Utopismo. Hiparquia, IX, n. 1, p.33-49, Jul.1997.

SAXONHOUSE, A. W. The Philosopher and the Female in the political thought of Plato. In: TUANA, Nancy (Ed.). Feminist interpretations of Plato. University Park: The Pennsylvania University Press, 1994. p.67-86.

SONTAG, S. Against Interpretation and other Essays. New York: Farrar, Straus \& Giroux, 2003.

TUANA, N. Introduction. In: TUANA, Nancy (Ed.). Feminist interpretations of Plato. University Park: The Pennsylvania University Press, 1994. p.3-19.

VAZ, H. C. L. Ética e Filosofia. Platonica. Escritos de Filosofia, v. VIII, São Paulo, Loyola, p.153-171, 2001.

VEGETTI, M. Guida alla lettura della Repubblica di Platone. 4. ed. Roma: Laterza, 2007.

VLASTOS, G. The Argument in the Republic that "Justice Pays". The Journal of Philosophy, v. 65, n. 21, p. 665-674, Nov. 7, 1968. Stable URL: <http://www.jstor.org/stable/2024542>. Accessed: 23 Jul. 2010.

VLASTOS, G. Was Plato a feminist? In: TUANA, Nancy (Ed.). Feminist interpretations of Plato. University Park: The Pennsylvania State University Press. 1994. p.11-13. 